\title{
Inhibitory learning and memory in the topshell (Monodonta lineata)
}

\author{
W. F. ANGERMEIER, M. BENECKE, B. GÖHLEN, and V. KOLLOCH \\ Marine Behavior Research Station, Lettermullen, Ireland \\ and Universität zu Köln, Köln, Germany
}

\begin{abstract}
One hundred eighty topshells (Monodonta lineata) were exposed to inhibitory learning procedures. Results indicate that (1) topshells are capable of inhibitory learning, (2) long-term memory for this type of learning persists for at least 32 days, and (3) topshells housed in groups of 10 learned more efficiently than did those housed in groups of 5 . The latter groups, however, learned more efficiently than did animals housed singly. These results were interpreted in terms of the evolutionary significance of such behavior.
\end{abstract}

Learning and remembering to inhibit a naturally occurring response must be deemed a biologically important capability of all organisms. By testing phylogenetically older organisms, we get some idea at what stage during the evolutionary process this capability appeared (Angermeier \& Dassler, 1992). In some instances, it also seems to make sense to suppose that an early appearance of certain behavior patterns helped the organism to adapt to and survive in changing environments.

Successful tests on inhibitory learning and memory were recently conducted with the lesser octopus (Eledone cirrhosa) in our laboratories (Angermeier \& Dassler, 1992). In the experiment reported here, we went one step further and studied the behavior of the topshell (Monodonta lineata), an early relative of the octopus, which had evolved about 50-100 million years earlier.

Although a great deal of biological information has been published about topshells, virtually no data are available about their behavior (Clarke, Kendall, \& Gore, 1990; Daguzan, 1991; Garwood \& Kendall, 1985; Little, Dicks, \& Crothers, 1986; Underwood, 1973; Williamson \& Kendall, 1981). We therefore designed an experiment to answer the following question: Is the topshell (Monodonta lineata) capable of learning not to extend its foot for suction on a surface and then able to store this learned inhibition in long-term memory?

\section{METHOD}

\section{Subjects}

The subjects were 180 topshells (Monodonta lineata) that were collected on the Atlantic shores of Western Ireland. The animals weighed between 3 and $8 \mathrm{~g}$. Immediately after their arrival in the laboratory, the animals were divided into three major groups designated by the way they were housed during the course of the experiment: housed singly (ones), in groups of five (fives), and in groups of ten (tens). The size of the glass jars used for housing had a volume of approximately $1,500 \mathrm{cc}$ and contained some small rocks overgrown with lichen (serving as food

Correspondence should be addressed to W. F. Angermeier, Psychologisches Institut, Universität zu Köln, Zülpicher Strasse 45, 5000 Köln 41 (Lindenthal), Germany. for the animals). The jars were filled with $1,000 \mathrm{cc}$ of seawater, which was changed daily during the course of the experiment.

\section{Apparatus}

The apparatus consisted of a small block of wood and a glass plate $(6 \times 24 \mathrm{~cm})$. One end of the glass plate rested on the wooden block, and the other end rested on a table, thus creating an angle of $25^{\circ}$. Beneath the glass plate was a mirror covered with black paper, out of which a square of $2 \times 2 \mathrm{~cm}$ was cut to permit visual inspection of the opening of the topshell. At the same time, the black paper prevented any lightsensitive reaction of the animal to the mirror.

\section{Procedure}

One day after the animals were collected, they were placed singly on the glass plate, directly above the small square hole in the paper on top of the mirror underneath. A stopwatch was started and was stopped when the animal had attached itself fully with its foot to the glass plate. When this happened, the animal was removed with a gentle pull, the foot was prevented from extending with the aid of a rubber-tipped pencil for $10 \mathrm{sec}$, and the animal was replaced on the glass plate. This procedure was repeated during the daily trial runs until the animal did not extend its foot during a period of $300 \mathrm{sec}$. Then the animal was placed back into its housing jar. Altogether, daily trials were administered on 5 consecutive days to all animals. Memory tests were performed 2, 6, and 32 days later, using the same criterion procedure as above. Since there were no significant differences between the memory data, they were treated as one unit during further analyses.

The rationale for this procedure was as follows. Sucking to a surface seems to be of high biological value to the topshell: One, it prevents the animal from being blown away by the ever-present winds, and, two, it aids in finding food (lichen). If this response can be inhibited, it shows that the animal is capable of learning. And if this learned response prevails over days and longer periods of time, it shows the animal's longterm memory abilities.

\section{RESULTS}

The following results were obtained from a series of pilot studies preceding this experiment: (1) Volume of water in the housing jar had no effect on the sucking behavior; (2) there was, furthermore, no difference in the sucking behavior between groups tested on clean glass surfaces and those tested on unclean surfaces (in the former situation, the testing glasses were cleaned after each animal's run, whereas in the latter situation, they were not cleaned); and (3) there were no differences in sucking behavior of animals tested in their natural environment (on 


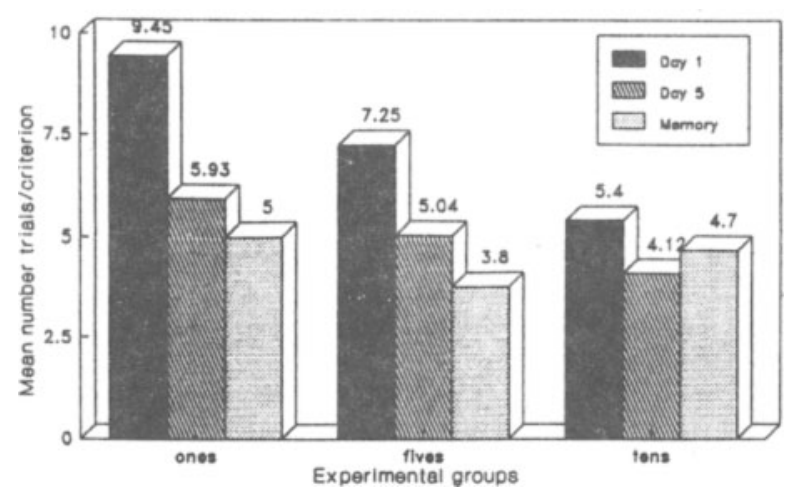

Figure 1. Mean number of trials-to-criterion $(N=180-60$ each for the living conditions of ones, fives, and tens).

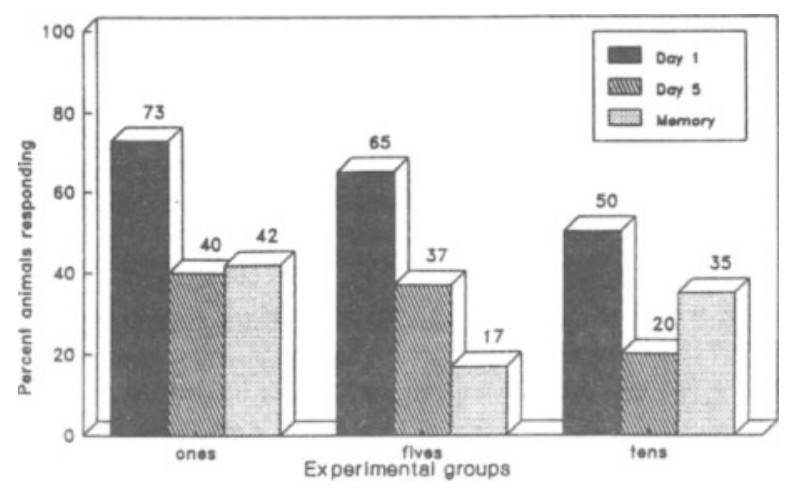

Figure 2. Percentage of animals responding $(N=180-60$ each for the living conditions of ones, fives, and tens).

the rocks near the shore, where they were living) and animals housed singly in the laboratory. A total of 76 subjects were used in these preliminary tests.

A simple analysis of variance, using number of suctions, resulted in $F(2,17)=31.32, p<.001$. A critical $d$ showed that number of suctions was significantly different for the three groups of ones, fives, and tens. These results are shown graphically in Figure 1.

A chi-square test performed on number of animals in all three groups showing more suctions on Day 1 than on Day 5 produced $\chi^{2}(1) 7.88, p<.01$. A further chisquare test performed on number of animals showing more suctions on Day 1 than during the memory tests-performed 2,6 , and 32 days later-produced $\chi^{2}(1)=10.00$, $p<.01$. Statistical tests probing differences between number of suctions on Day 5-the last day of the testand those during the memory tests were not significant.

The number of animals responding on Days 1 and 5 and during the memory tests are shown in Figure 2.

Statistical analyses showed that there was a significant difference between the number of animals responding at all (at least one foot extension for sucking) on Day 1 and those responding on Day $5\left[\chi^{2}(1)=8.35, p<.01\right]$, but not between number of animals responding at all on Day 5 and those responding during the memory tests.

\section{DISCUSSION AND CONCLUSIONS}

There were three major findings in this experiment, of which two are more easily explained than the third. The statistically significant differences of foot extensions between Day 1 and Day 5 indicate that inhibitory learning had taken place. The significant difference of foot extensions between Day 1 and the memory tests shows that the learned inhibition was also available in long-term memory. The strength of that inhibition remains seemingly unchanged, according to tests comparing foot extensions on Day 5 and memory tests 2, 6, and 32 days later.

The major differences between number of animals in one housing jar $(1,5$, or 10 subjects) are more difficult to explain. Neither volume of water (correlated with degree of cleanliness) nor cleanliness of the testing surface showed any significant influence on the behavior studied here. Thus, we can virtually eliminate these factors as an important variable.

During calm weather conditions, Monodonta lineata are more widely dispersed upon the rocks on the shore than they are during windy weather conditions and move as much as $4 \mathrm{~m}$ during one tidal cycle, as Courtney (1972) observed. These calm conditions prevailed in our laboratory during the experiment. Underwood (1972) observed in a laboratory study, simulating normal changes in tidal conditions, that animals showed more movement in the laboratory than in nature during the same time periods and that Monodonta lineata's movements were not influenced by the rise or fall of the water in the testing tank. The three observations taken together indicate that it was perhaps the restriction of free space for movement in the housing jar, caused by the difference of the number of animals housed in one jar, that was responsible for the decrease of suction responses with the increase of number of animals housed together. Experiments designed to throw more light on this hypothesis are now in progress.

The fact that this behavioral capability is present in a phylogenetically "older"' animal attests to the evolutionary significance of inhibitory learning - that is, learning not to exhibit and/or to suppress certain naturally occurring behavioral responses.

\section{REFERENCES}

Angermeier, W. F., \& Dassler, E. (1992). Inhibitory learning and memory in the lesser octopus (Eledone cirrhosa). Bulletin of the Psychonomic Society, 30, 309-310.

Clarke, A., Kendall, M. A., \& Gore, D. J. (1990). The accumulation of fluorescent age pigments in the trochid gastropod Monodonta lineata. Journal of Experimental Marine Biology \& Ecology, 144, 185-204.

Courtney, W. A. M. (1972). The effect of wind on shore gasteropods. Journal of Zoology, 166, 133-139.

Daguzan, J. (1991). Studies of the growth and ecology of Monodonta lineata da Costa gastropoda Prosobranchia Trochidae living on the Atlantic coast of Brittany, France. Cahiers de Biologie Marine, 32, 3-22.

GARWOOD, P. R., \& Kendall, M. A. (1985). The reproductive cycles of Monodonta lineata and Gibbula umbilicalis on the coast of midWales, U.K. Journal of the Marine Biological Association of the United Kingdom, 65, 993-1008.

Little, A. E., Dicks, B., \& Crothers, J. H. (1986). Studies of barnacles, limpets and topshells in Milford Haven Dyfed, South Wales, U.K. Field Studies, 6, 459-492.

UNDERWOOD, A. J. (1972). Time model analysis of the zonation of intertidal prosobranchs: II. Four species of trochids (Gastropoda Prosobranchia). Journal of Experimental Marine Biology \& Ecology, 9, 257-277.

UNDERWOOD, A. J. (1973). Studies on zonation of intertidal prosobranch mollusks in the Plymouth region. Journal of Animal Ecology, 42, 353-372.

Williamson, P., \& Kendall, M. A. (1981). Population age structure and growth of trochid Monodonta lineata, determined from shell rings. Journal of Marine Biological Association of the United Kingdom, 61, 1011-1026.

(Manuscript received June 7, 1993.) 